\title{
Cracking Process in Delayed Fracture of High-Strength Steel after Long Atmospheric Exposure
}

\author{
Tomoka HOMMA,${ }^{1)}$ Takahiro CHIBA, ${ }^{1)}$ Kenichi TAKAI, ${ }^{2)}$ Eiji AKIYAMA, ${ }^{3)}$ Wataru OSHIKAWA ${ }^{4)}$ and \\ Michihiko NAGUMO ${ }^{5) *}$ \\ 1) Graduate School, Sophia University, 7-1 Kioi-cho, Chiyoda-ku, Tokyo, 102-8544 Japan. \\ 2) Department of Engineering and Applied Science, Sophia University, 7-1 Kioi-cho, Chiyoda-ku, Tokyo, 102-8544 Japan. \\ 3) Institute for Materials Research, Tohoku University, Katahira 2-1-1, Aoba-ku, Sendai, 980-8577 Japan. \\ 4) Faculty of Engineering, University of the Ryukyus, Nakagami-gun, Okinawa, 903-0213 Japan. \\ 5) Laboratory for Materials Science and Technology, Waseda University, NishiWaseda 2-8-26, Shinjuku-ku, Tokyo, 169-0051 \\ Japan.
}

(Received on May 31, 2021; accepted on December 20, 2021; J-STAGE Advance published date:

February 12, 2022)

\begin{abstract}
This paper is the first microscopic observation of the entire cracking process in delayed fracture of highstrength steel bolt after long-term atmospheric exposure. A sufficiently fresh fracture surface exhibits the initiation of the propagating crack in a thin zone beneath the screw groove, resulting from the merging of multiple cracks nucleated therein. The fracture morphology is initially intergranular, exhibiting the threedimensional shape of prior austenite grains, but the stress and strain states at the nucleation sites are not uniquely specified. The fracture morphology alters as the crack extends from intergranular to quasicleavage and fine dimples, associated with increasing stress intensity under a constant-displacement condition. The change from inter- to trans-granular fracture is continuous, implying affinity among different morphologies associated with the increased density and the distribution of potential crack nucleation sites in the crack front. The crack propagation in the quasi-cleavage and fine dimple regions is step-wise of about $50 \mu \mathrm{m}$ per step. Recent studies about the function of hydrogen in embrittlement are referred to in respect of the accumulation of strain-induced damage. The enhanced generation of strain-induced vacancies is the presumable function of hydrogen compatible with the present findings.
\end{abstract}

KEY WORDS: hydrogen embrittlement; delayed fracture; high-strength steel; atmospheric exposure; fractography; cracking.

\section{Introduction}

Eventual failure in a long-term service is crucial to structural steel components. Failure takes place in service, often extending over many years, even in mildly corrosive environments. The susceptibility to failure increases with increasing material strength, and the risk of failure hinders growing industrial needs for higher strength steels by imposed limitations on their allowable usage levels. ${ }^{1,2)}$ Delayed fracture has been widely accepted as a type of hydrogen embrittlement (HE) commonly occurring in tensile or bending tests regarding the hydrogen-content dependence of the susceptibility and characteristic fractographic features. Hydrogen is generated as a by-product of surface corrosion in mildly corrosive environments, and HE is distinguished from stress corrosion cracking (SCC) dominated

\footnotetext{
* Corresponding author: E-mail: nagumo@waseda.jp
}

by anodic dissolution that forms corrosion pits.

Studies of delayed fracture in laboratories meet difficulty in simulating atmospheric exposure. Laboratory tests are in most cases conducted under intensified hydrogen environments and loading modes different from practical use ${ }^{3-5)}$ to perform the tests in a short time, say one week or so. As for the understanding of hydrogen problems, the molecular precipitation of residual hydrogen is a well-established cause of early problems such as internal cracking of wrought steels and weldments, ${ }^{6}$ but the hydrogen fugacity expected from observed hydrogen concentrations in atmospheric exposure is very low. ${ }^{7-9)}$ The manifestation of HE is diverse depending on experimental conditions such as materials, loading conditions, hydrogen environments, evaluation parameters so on, as compiled in a textbook. ${ }^{10)}$ The function of hydrogen in embrittlement is not sure to be the same depending on phenomena and situations.

From a fundamental viewpoint as fracture event, a char- 
acteristic of delayed fracture is that it proceeds under constant-stress or -strain conditions without a rising load that enhances dislocations motion or induces lattice decohesion. A significant incidental increase in applied stress necessary to overcome the energy barrier to fracture is hardly feasible. It implies that the driving force to fracture originates in a mechanism other than a mechanical one. The current mainstream idea on the origin of delayed fracture is that the local hydrogen concentration reaches a critical level, $\left.\mathrm{H}_{\mathrm{cr}}{ }^{*}{ }^{3}, 11,12\right)$ An experimental measure of $\mathrm{H}_{\mathrm{cr}}{ }^{*}$ in laboratory sustainedloading tests is the lowest mean hydrogen concentration $\mathrm{H}_{\mathrm{cr}}$ that causes delayed fracture using hydrogen-precharged specimens. ${ }^{3,13,14)}$ The incubation time to the onset of delayed fracture is then time to attain $\mathrm{H}_{\mathrm{cr}}{ }^{*}$. Diffusion of internal hydrogen to the crack nucleation site such as highly-stressed one determines the incubation time in hydrogen-precharged specimens. ${ }^{13)}$ The incubation time is zero without further increased hydrogen concentration when enough precharged hydrogen is present. ${ }^{3)}$ On the other hand, the supply of hydrogen or an increase in absorbed hydrogen to attain $\mathrm{H}_{\text {cr }}{ }^{*}$ is requisite in the case of low initial concentrations of hydrogen, such as atmospheric exposure.

However, a crucial fact against the idea is that an initial increase in hydrogen content ceased within one year in atmospheric exposure and then turned to saturate or even decrease with time. ${ }^{7-9)}$ The idea of $\mathrm{H}_{\mathrm{cr}}$ in evaluating $\mathrm{HE}$ may be valid when the supply of hydrogen is the ratedetermining process in fracture. The idea of $\mathrm{H}_{\mathrm{cr}}$ is intuitively acceptable, and lattice-decohesion models ${ }^{15-17)}$ that presume reduction of the cohesive force by hydrogen is a theoretical background for $\mathrm{H}_{\mathrm{cr}}$. Assuming that lattice hydrogen reduces the cohesive force of atomic bonds, Oriani and Josephic estimated the critical local hydrogen concentration $\mathrm{C}_{\mathrm{H}}$ at the crack-tip to fit the experimentally determined critical stress intensity factor $K_{\text {cr }}$ for the start of cracking in a wedge opening loading test of AISI 4340 steel in hydrogen gas. ${ }^{15)}$ The addressed fracture mode was intergranular. Oriani and Josephic considered the accumulation of hydrogen at the crack-tip caused by the intensified stress field and the segregation along grain boundaries. The stress intensification attained magnitude as large as $10^{4}$ of the stress-free hydrogen concentration assuming the crack-tip radius of 2.5 $\mu \mathrm{m}$ and the grain boundary segregation of over $10^{3}$ lattice hydrogen. The estimated $\mathrm{C}_{\mathrm{H}}$ along grain boundaries was more than $10^{-2}$ at the crack-tip. The associated reduction in the cohesive force was to 0.34 of the hydrogen-free case. Li et al. measured the hydrogen concentration in circumferentially notched bar specimens of the same steel used in the present study. After atmospheric exposure, the mean concentration was around 5 at. ppm including trapped hydrogen at various lattice defects in martensitic steels. ${ }^{9)}$ When assumptions made in Ref. 15), i.e. the multiplication by $10^{4}$ due to stress intensification and the inclusion of trapped hydrogen, are accepted, the observed mean hydrogen concentration gives $\mathrm{C}_{\mathrm{H}}$ of $5 \times 10^{-2}$ in agreement with Ref. 15).

A contrastive aspect of HE of steel against lattice-decohesion is the concern of local plasticity. A well-documented interaction between hydrogen and plasticity is the enhancement of dislocation mobility (hydrogen-enhanced local plasticity, HELP, mechanism) ${ }^{18-20)}$ However, the enhanced mobility of dislocations per se is not a mechanism of embrit- tlement. The transport of hydrogen by activated dislocations was then assumed to promote decohesion of boundaries (HELP-mediated decohesion). ${ }^{21,22)}$ This model was applied to gain an understanding of characteristic fractographic features in HE, such as intergranular (IG) and quasicleavage (QC) fracture. The model presumes dislocations glide over a fairly long distance. However, the assumed substantial gliding of dislocations needs a critical examination in delayed fracture without an increasing load. A typical case to be examined is martensitic steels that consist of fine structural units of the order of $\mu \mathrm{m}$ associated with walls of high dislocation densities.

On the other hand, an unmissable outcome of mutual interactions of moving dislocations is the generation of point lattice defects. The drag of jogs ${ }^{23)}$ and pair annihilation of edge dislocations ${ }^{24,25)}$ were feasible processes for generating high densities of vacancies, and the computed densities amounted to $10^{-3}-10^{-4}$ in the dislocation-rich sites such as in multiple-glide slip bands ${ }^{23)}$ and dislocation cell walls. ${ }^{24,25)} \mathrm{A}$ crucial finding concerning $\mathrm{HE}$ is enhancing the strain-induced generation of vacancies by hydrogen, as demonstrated using hydrogen thermal desorption analysis ${ }^{26-28)}$ and positron annihilation spectroscopy. ${ }^{29-32)}$ Stabilization of vacancies by hydrogen has also been theoretically rationalized in terms of the thermodynamic equlibrium ${ }^{33)}$ and diffusion kinetic ${ }^{34)}$ aspects.

Excess vacancies tend to cluster forming a source of nanovoids. Nanoscopic features of QC fracture of line-pipe steels in hydrogen gas were identified as a "valley-onvalley" type coalescence of nanovoids by mating conjugate fracture surfaces, indicating nanovoid nucleation and growth consistent with vacancy clustering. ${ }^{35)}$ Concerns of the hydrogen enhancement of the strain-induced generation of vacancies (HESIV mechanism) with HE of steels were compiled in review articles. ${ }^{36,37)}$

A crucial implication of the HESIV mechanism is the supplementary function of hydrogen in embrittlement: embrittlement appeared even though hydrogen was not present at the final stage in tensile tests. It was demonstrated by tensile tests of hydrogen-precharged iron and Inconel 625 alloy with interposed unloading and reloading ${ }^{38)}$ diffusing out of hydrogen at the unloaded stage still deteriorated tensile ductility while annealing out of both hydrogen and strain-induced vacancies fully recovered ductility. The experiments demonstrated the predominant role of vacancies rather than hydrogen itself in HE. The finding also exhibited the contribution of precursory damage to deterioration at the final fracture stage. Such findings, as a consequence, shifted the aspect to the primary factor for degradation from hydrogen to vacancies.

As stated above, the involvement of plasticity and its role in the HE of steels is a current critical issue in dispute. Recent studies on HE of steels concerning to involvement of plasticity are substantial, ${ }^{37,39)}$ but the delayed fracture in atmospheric environments has been out of intense studies. Accurate simulation of delayed fracture that occurs in atmospheric exposure is complex in laboratory tests, and getting proper materials for detailed fracture analysis also meets difficulty. Observations of the fractographic features are very limited to the best of our knowledge. Available information is simply the intergranular type of fracture around 
the crack initiation site in high-strength steel bolts fractured after atmospheric exposure of $150^{40)}$ and about 300 days. ${ }^{41)}$

The scant supply of proper materials to be analyzed has limited knowledge about the nature of the delayed fracture in service. Fortunately, a precious sample that got rid of the difficulty was available by chance with a high-strength steel bolt subjected to atmospheric exposure for 16 years and retrieved within 24 hours after the fracture. The fracture surface was sufficiently clean for observing fine details. This paper first revealed microscopic sequence of cracking in the delayed fracture of high-strength steels after long-term atmospheric exposure. The material provided a chance to examine the operating mechanism of $\mathrm{HE}$ in engineering practice. Conformity of the present findings with recent advances in understanding the mechanism of HE is the main subject of discussion.

\section{Experimental Procedure}

\subsection{Material and Exposure Test}

The failed bolt examined in this study was one of 100 high-strength steel bolts subjected to atmospheric exposure as a part of a joint research program by the Japan Iron and Steel Federation, Building Research Institute, and National Institute for Materials Science. The steel was a medium carbon Cr-Mo steel, SCM435 in the Japanese Industrial Standard (JIS) similar to AISI 4135. The chemical compositions and acicular martensitic microstructures are shown respectively in Table $\mathbf{1}$ and Fig. 1. The steel was oil quenched from $1133 \mathrm{~K}$ and subsequently tempered at $733 \mathrm{~K}$ for $110 \mathrm{~min}$ followed by water quenching. Tensile properties of the steel after heat treatments are shown in Table 2. The screw-threaded bolt was a JIS hexagon head bolt of $22 \mathrm{~mm}$ in diameter and $85 \mathrm{~mm}$ in shank length. It was fastened to a steel plate of $45 \mathrm{~mm}$ in thickness through a hole of $22.7 \mathrm{~mm}$ in diameter with a nut and two washers to the axial force of $346 \mathrm{kN}$. The orientation of bolts was

Table 1. Chemical compositions of the steel (mass\%).

\begin{tabular}{cccccccc}
\hline $\mathrm{C}$ & $\mathrm{Si}$ & $\mathrm{Mn}$ & $\mathrm{Ni}$ & $\mathrm{Cr}$ & $\mathrm{Mo}$ & $\mathrm{P}$ & $\mathrm{S}$ \\
\hline 0.38 & 0.17 & 0.69 & 0.02 & 1.02 & 0.18 & 0.015 & 0.016 \\
\hline
\end{tabular}

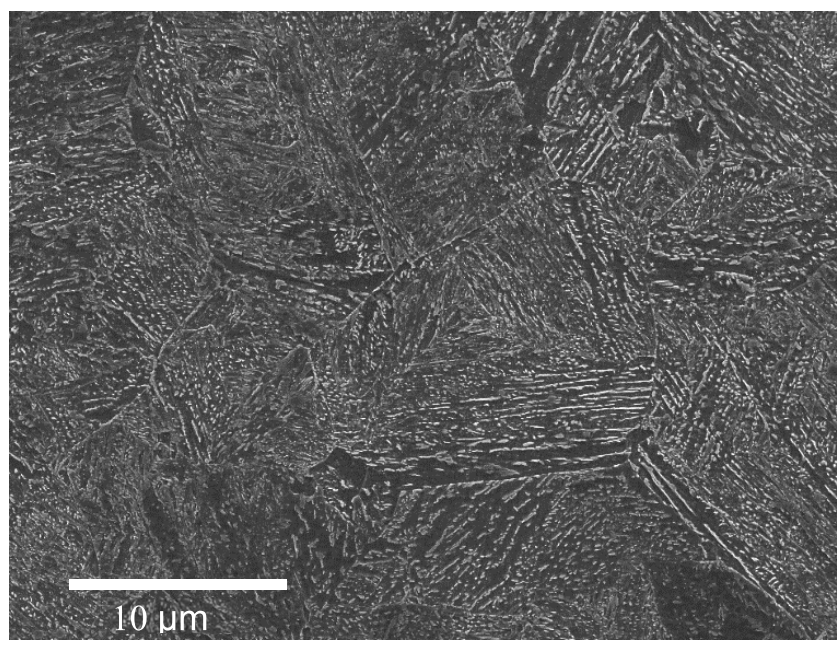

Fig. 1. Scanning electron micrograph of microstructures of the steel (Etched with 5\% nital). horizontal during exposure.

The atmospheric exposure started on June 17th, 2003, on the roof of a factory located at a site about $50 \mathrm{~m}$ apart from the coast in Ginowan City, Okinawa, Japan. The exposure site was moved on January 21st, 2009, to the roof of a building on the campus of University of the Ryukyus in Nakagami-gun. The site is about $2.5 \mathrm{~km}$ from the coast, and the average amount of salt in the air is 0.45 minimum detectable dose $\left(\mathrm{mg} / 10^{-2} \mathrm{~m}^{2}\right.$.day). After 16 years of exposure, failure of a bolt was found and retrieved on October 1st, 2019, within 24 hours after the fracture. At the time of failure, the end part of the broken bolt dropped down with the fastening nut, and the head part of the bolt remained in the attached steel plate. Fractographic features of the remained head part were the subject of detailed observation in the present study.

Loading of the bolt was under a constant-displacement mode. The axial force for fastening is shown in Fig. 2. The final axial stress exceeded the elastic limit, and the stress concentration at the screw groove enhanced plastic deformation in the region close to the root. The maximum principal stress and equivalent plastic strain along the screw-threaded shank were calculated using a finite element method (MSC. Marc2005r2). ${ }^{42)}$ The results were compared with those of circumferentially V-notched round bar specimens, ${ }^{42)}$ and it was shown that the $\mathrm{V}$-notch radius of $0.25 \mathrm{~mm}$ was a good approximation of the Japan Industrial Standard screwthreaded bolts. ${ }^{42)}$ The stress and strain distributions beneath the V-notch root were then calculated and shown in Fig. 3. Figure 3 includes results for four high-strength steels, including the present one under the same applied stress as used here. ${ }^{42)}$ The curves with the ordinate normalized by

Table 2. Tensile properties of the steel. 0.2 PS: $0.2 \%$ proof stress, UTS: ultimate tensile stress, El: elongation to fracture, RA: reduction of area.

\begin{tabular}{cccc}
\hline $0.2 \mathrm{PS}$ & UTS & El & RA \\
\hline $1202 \mathrm{MPa}$ & $1312 \mathrm{MPa}$ & $15.8 \%$ & $53.4 \%$ \\
\hline
\end{tabular}

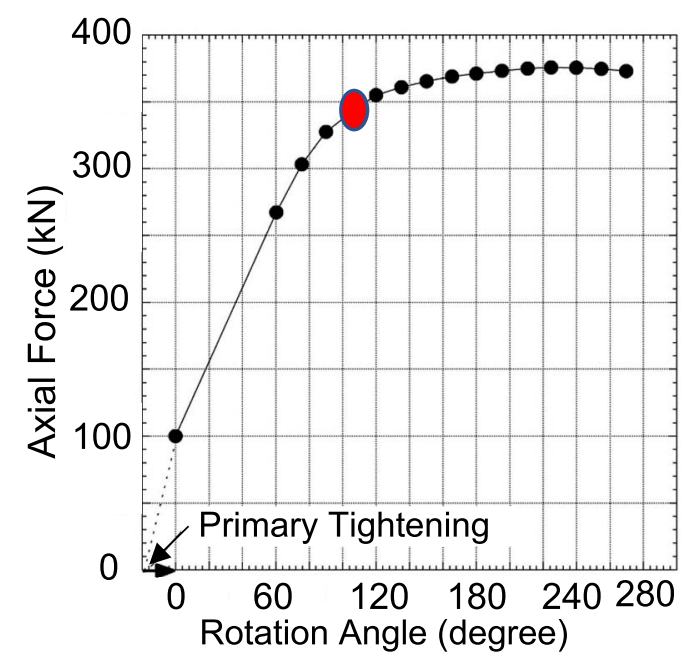

Fig. 2. Axial force on fastening a bolt by rotating nut. The ordinate denotes the rotating angle after primary tightening. The red mark indicates the present case. (Online version in color.) 


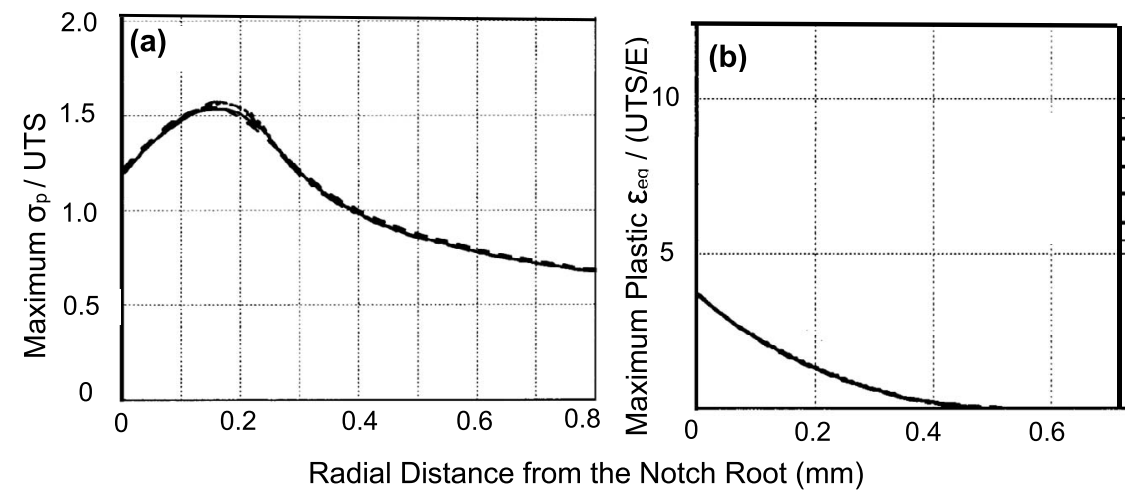

Fig. 3. Finite element method calculations of stress and plastic strain along the radial direction. (a) Maximum principal stress $\sigma_{\mathrm{p}}$ normalized by ultimate tensile stress. (b) Maximum equivalent plastic strain $\varepsilon_{\mathrm{eq}}$ normalized by elastic fracture strain (= ultimate tensile stress/Young's modulus E). The diameter of the bar was $10 \mathrm{~mm}$, and the $60^{\circ} \mathrm{V}$ circumferential notch was $2 \mathrm{~mm}$ in depth with a root radius of $0.25 \mathrm{~mm}$. Calculations were conducted for four high-strength steels of 1 313, 1 492, 1 455, $1772 \mathrm{MPa}$ in UTS and 1 202, 1 304, 1 345, 1596 in 0.2\% PS, respectively. Young's modulus and Poisson's ratio were commonly set at $205 \mathrm{GPa}$ and 0.3 , respectively.

the UTS are insensitive to the type of steel, and the curves for the four steels are almost overlapping. Failure in the present case occurred at the second groove from the start of screw-grooving. The thickness of the fastened steel plate and two washers fixed the distance between the bolt head and the nut. The axial force is the product of the elastic stress and the cross-sectional area of the shank. In the crack propagation stage, the decrease in the cross-sectional area reduces the axial force. Still, the elastic displacement in the ligament is constant, implying that the applied elastic stress there unaltered except in the crack front region where the stress intensification operates. An increment in the thickness of the fastened plate due to the reduced compression was negligibly small.

\subsection{Observation of Fracture Morphology}

Field-emission scanning electron microscopy (JEOL JSM-7001F) using secondary electrons was conducted at an operating voltage of $10 \mathrm{kV}$. MeX software that constructs a three-dimensional image from three SEM images taken from three directions was used in the present study for the fracture surface, tilting the sample stage $-5^{\circ}, 0^{\circ}$, and $+5^{\circ}$. Under the application of an increasing load to a specimen, failure is to begin at some weak spots or stress concentrator in the form of a microcrack or microvoid. MeX was also applied to fracture surface topography analysis (FRASTA) that detects the crack nucleation and propagation process on a computer. ${ }^{40,43)}$ Three-dimensional images of mating fracture surfaces are first fully coalesced and then successively separated on the computer. The extension of the open area following the increase in the separation distance " $\mathrm{s}$ " is recorded.

\section{Results}

\subsection{Crack Initiation}

\subsubsection{Multiple Crack Nucleation and Mergence}

Figure 4 shows optical micrographs of pair fracture surfaces of the broken bolt. Small rust spots in Fig. 4(a) were not so frequent over the entire fracture surface, and their size was too small to discern. The retrieve of the broken bolt was

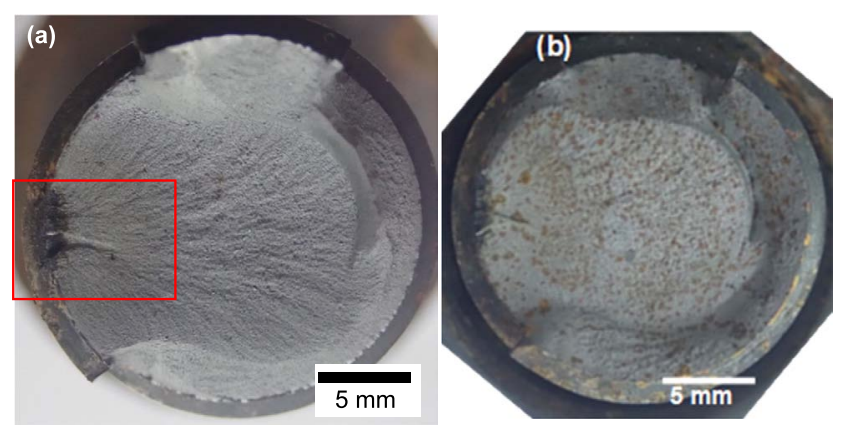

Fig. 4. (a) Optical micrograph of the entire fracture surface and (b) the pair fracture surface of (a). (Online version in color.)

within 24 hours after fracture, but the presence of slight rusting suggested that a once nucleated crack did not propagate catastrophically. Figure 4(b) is the surface of the opposite side of the broken bolt that dropped down on failure. Rust stain was explicit on this side. The progress of rusting different from Fig. 4(a) is likely due to the environment. Exposure to an open environment after dropping was a possible cause of advancing rusting. Another supposed cause of rusting is the entering of rain or condensed water onto the end part of the bolt. Screw grove of the nut might be a path of water and air from environment. A small gap also might form between the bolt and the steel plate by a reduced axial force associated with the crack propagation preceding the final separation. The optical micrographs empirically suggested that roughly one week or so had passed after the initiation of cracking until the final separation. Before the retreat of the bolt on October 1, 2019, it was rainy on September 29, and a typhoon hit on September 19-22.

Figure 5(a) is a magnified optical micrograph of the dark part in the left edge of the surface in Fig. 4(a). The part is seemingly affected by heavy rusting, and small particles indicated by yellow arrows in Fig. 5(a) are likely rust spots. However, corrosion pits or thick corrosion films were not observable. Magnified SEM micrographs in later Figs. 9 and 12(a) also exhibited sharp IG fracture surfaces not affected by corrosion. Dark contrasts in Figs. 4 and 5(a) are 
likely due to thin surface materials and inclination of the surface. Figure 5(b) is a magnified SEM micrograph of the red-framed area in Fig. 4(a). The contrasts in Figs. 5(a) and 5(b) are different likely because of each principle of imaging. Fracture morphologies successively altered associated with the crack propagation as described later in Sec. 4.2. Fan-like patterns in Fig. 5(b) in the crack propagation stage correspond to the alteration of fracture morphologies. The origins of fan-like patterns and a dark part in the middle of Fig. 5(b) are primarily due to the roughness of the fracture surface.

Broad radial striations present in Figs. 4(a) and 5(a) indicate that the propagating crack started from the dark area near the edge of the fracture surface. The striations are not distinct in the dark area and do not converge to one point. The striations emerge from a thin zone with highly dark contrast of several hundred $\mu \mathrm{m}$ in thickness and a few $\mathrm{mm}$ along the edge according to the length scale in Fig. 5(b). The zone was likely the initiation site of the final propagating crack. The zone corresponds to the highly stressed and strained region in Fig. 3. We define the term "initiation" as the starting stage of the finally propagating crack. The idea of "initiation" is like the instability of the incipient crack in Griffith theory for brittle fracture, but the initiation in the

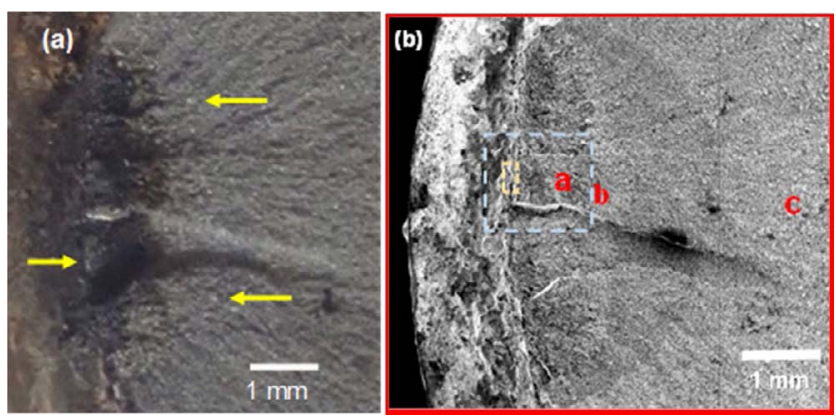

Fig. 5. (a) Magnified optical micrograph of the dark area in the left side of Fig. 4(a). Yellow arrows indicate small particles likely of rust-spots. (b) SEM micrograph of an area near the crack initiation site indicated by the red frame in Fig. 4(a). The blue and yellow dashed frames indicate the areas in Figs. 6(a) and 9(a), respectively. Letters a, b and c indicate the sites of areas (a), (b) and (c), respectively, in Fig. 12. (Online version in color.)
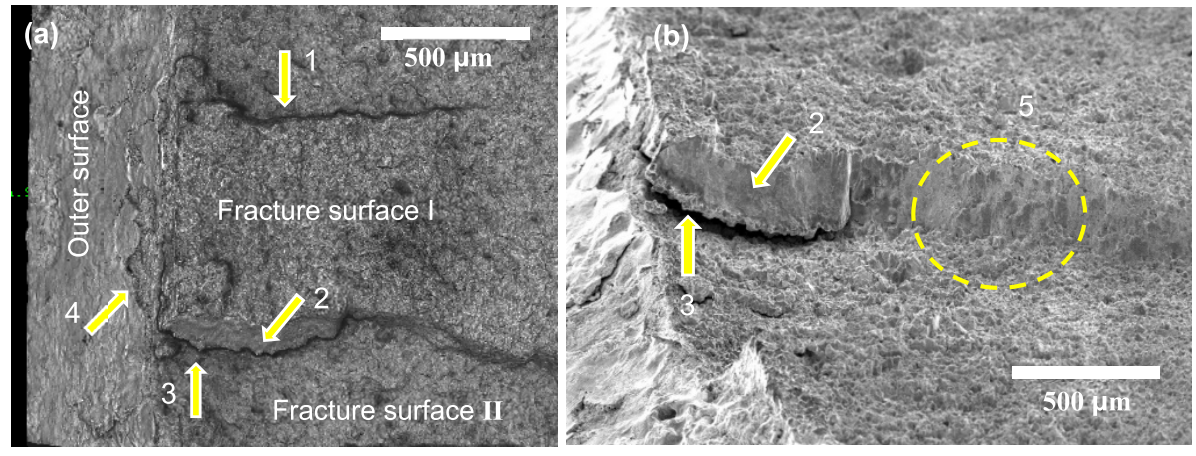

Fig. 6. SEM images of the crack initiation site. (a) Downward 3-dimensional image showing multiple cracks on the fracture surface; arrows 1 and 2 indicate steps between neighboring crack surfaces on different planes. Arrow 4 is a crack that developed on the outer surface of the bolt. (b) SEM image tilting the specimen by $60^{\circ}$ around the horizontal axis (i.e., the crack growth direction) showing the details of an enlarged view of step 2. Arrow 3 indicates the opening between neighboring fracture surfaces, and circle 5 shows the mergence of two cracks on surfaces I and II. (Online version in color.) present case is not a catastrophic one from a point. On the other hand, the term "nucleation" in this paper indicates the formation of multiple microcracks prior to the start of the final propagating crack; the merging of nucleated cracks leads to the propagating crack.

Multiple cracks were present in the zone on neighboring planes separated by steps, and cracks on different planes merged to form a wide planar crack as shown in Fig. 6 by SEM. Figure 6(a) is a downward 3-dimensional image, and Fig. 6(b) is an image obtained by tilting the fracture surface by $60^{\circ}$ around the horizontal axis. Multiple crack nucleation was also manifested as numerous small cracks on the outer surface of the bolt as indicated by arrow 4 . The presence of cracks on the outer surface is also evident in Fig. 7. Arrows 1 and 2 in Fig. 6 indicate steps between cracks on neighboring planes and circle 5 shows their mergence to form a planar crack. The edge of fracture surface II was widely open from the upper part.

The propagating crack starting from the merging of the two cracks nucleated in a thin zone implies that the zone as a whole acted as the initiation site of the propagating crack. This finding characterizes fracture in the present case as being in contrast to "brittle" fracture in which a crack that nucleates at a specific point like second phase particles and

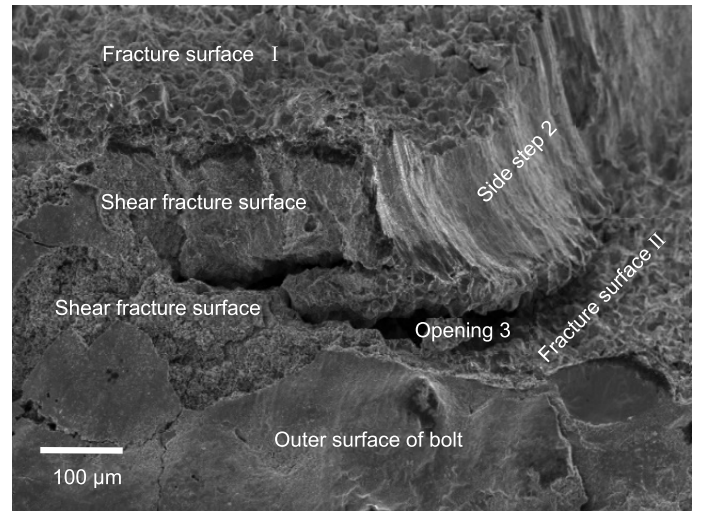

Fig. 7. SEM image of the intersection site of cracks with the outer surface of the bolt obtained by tilting the specimen in Fig. 6(b) by $60^{\circ}$ around the vertical axis. Side step 2 is the same as arrow 2 in Fig. 6. Fracture surface I reaches the outer surface forming shear fracture, whereas lower fracture surface II directly intersects the outer surface. 
grain boundaries propagates in an unstable way. ${ }^{6)}$

\subsubsection{Crack Initiation Sites: Crack Shape and FRASTA}

Figure 7 is a magnified SEM image of intersections of cracks with the outer surface of the bolt. Fracture surface I reached the outer surface of the bolt finally by shear fracture, while fracture surface II directly intersected the outer surface. The presence of shear fracture in fracture surface I is also shown in Fig. 9(a). It is seen in Figs. 6(b) and 7 that fracture surface I was fairly flat except the shear part, whereas fracture surface II was markedly curved. This difference in the crack shape implies that the operating stress and strain states are not the same by crack nucleation sites.

A method of following the cracking sequence is the
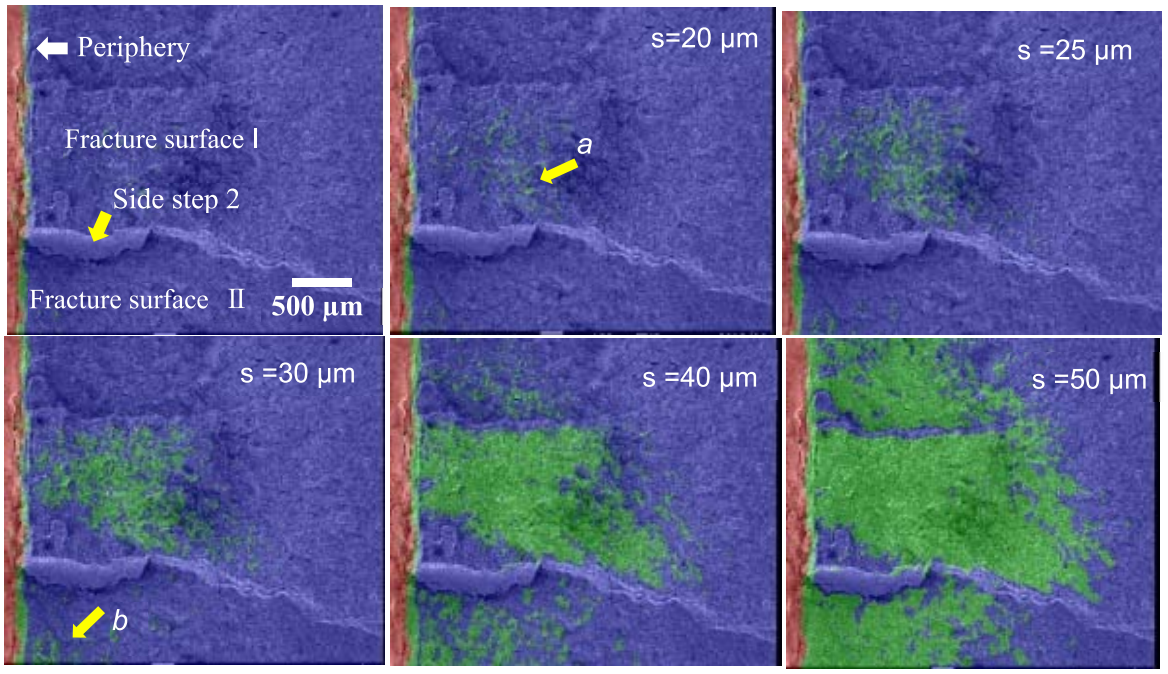

Fig. 8. FRASTA results for crack nucleation and propagation with increasing the separation distance between mating upper and lower fracture surfaces of the bolt. Separated parts are denoted in green. The separation distance is denoted by "s". Sites $a$ and $b$ are the first nucleation sites in each of the neighboring fracture surfaces. (Online version in color.)

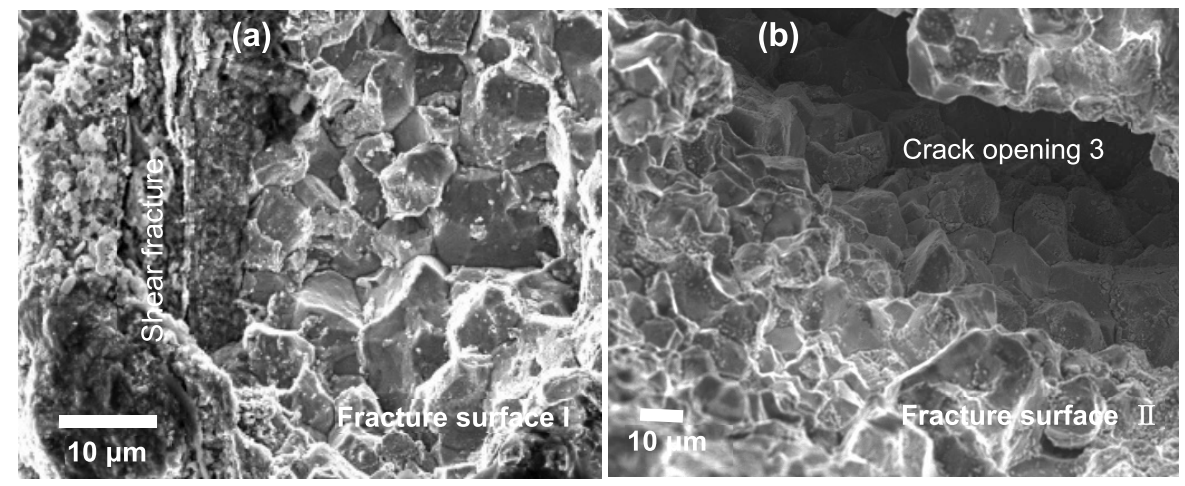

Fig. 9. (a) SEM micrograph of fracture surface I at the intersection with the outer surface of the bolt forming shear fracture. The area corresponds to the yellow dashed frame in Fig. 5(b). (b) SEM image of fracture surface II near and under crack opening 3 shown in Figs. 6 and 7. Both fracture surfaces I and II exhibit IG fracture.

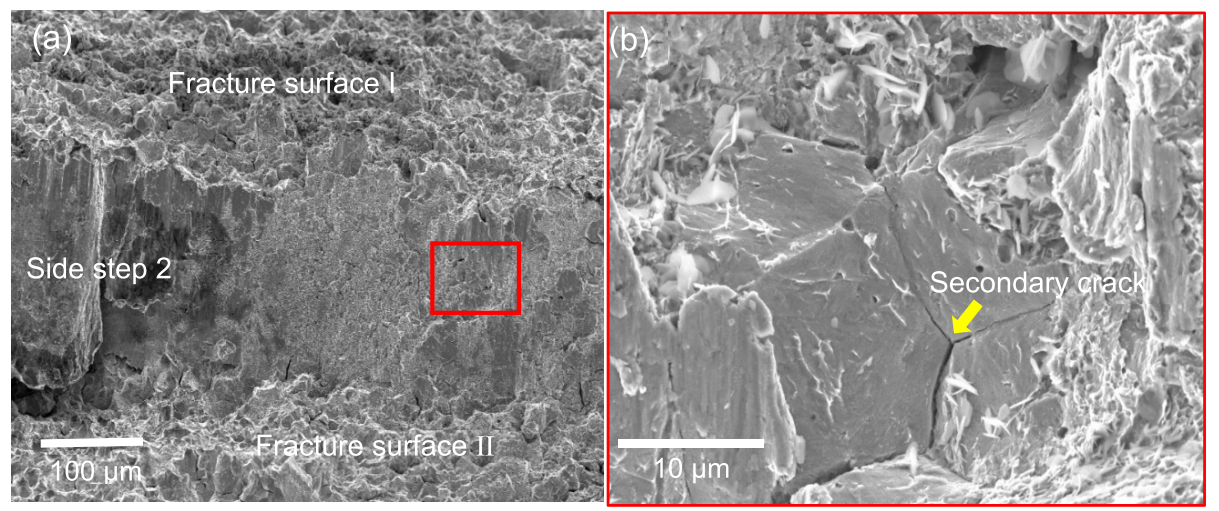

Fig. 10. (a) SEM image of the convergence area of fracture surfaces I and II indicated by circle 5 in Fig. 6(b), tilting the specimen by $60^{\circ}$ around the horizontal axis. (b) Magnified view of the red framed area in (a). Intergranular fracture sharply inclined from the horizontal plane is shown. (Online version in color.) 
FRASTA technique. The FRASTA results in Fig. 8 show successive separations, in green, of the mating fracture surfaces by a distance "s". Separation first appeared on fracture surface I at a site around $500 \mu \mathrm{m}$ from the edge as arrow $a$ indicates and the separation extended towards the edge. On the other hand, separation on fracture surface II first appeared at a site very close to the edge as arrow $b$ indicates and extended inward. According to the stress and strain distributions shown in Fig. 3, the stress and strain states at the first nucleation sites were substantially different on fracture surfaces I and II.

\subsubsection{Fracture Morphology}

Both fracture surfaces I and II in the crack nucleation zone exhibited IG as shown in Fig. 9 and later in Fig. 12(a). The area shown in Fig. 9(a) is within the dark area in the optical micrograph Fig. 5(a). Some tiny particles likely of corrosion products are present in Fig. 9, but sharp IG morphologies imply that heavy corrosion is not present. IG fracture is usually regarded as a typical type of tensile stresscontrolled brittle fracture, and previous studies assigned the crack initiation in delayed fracture to a site where a large tensile stress operated. ${ }^{40)}$ On the other hand, Fig. 10 shows the site where fracture surfaces I and II merged prior to the start of the propagating crack. The appearance of IG mode shown in Fig. 10(b) is similar to that shown in Fig. 9, but the fracture plane steeply inclines from the horizontal plane. Various orientations of adjacent IG surfaces also imply that externally applied tensile stress does not dominate IG fracture mode in the crack nucleation. Local stress states are complicated in the presence of multiple cracks and stress relief upon the crack nucleation. However, IG fracture mode was dominant over a zone of about $500 \mu \mathrm{m}$ in width, including sites close to the outer surface, as Figs. 7 and 9 showed. It is not definite that a specific stress or strain state controls the crack nucleation in the zone while the fracture mode is IG.

Multiple crack nucleation along prior austenite grain boundaries was also present beneath the outer surface of an unbroken part of the bolt. Figure 11 is a SEM micrograph of a cross-section parallel to the tensile axis beneath the screw groove second-next to the fractured surface. The observed area (a) was about $200 \mu \mathrm{m}$ from the groove root, showing multiple nucleation and branching of cracks along prior austenite grain boundaries. The presence of multiple cracks in the cross-section was consistent with those on the fracture surface shown in Figs. 6-8. The insert (b) in Fig. 11 is a magnified view of the red-framed area in (a), showing

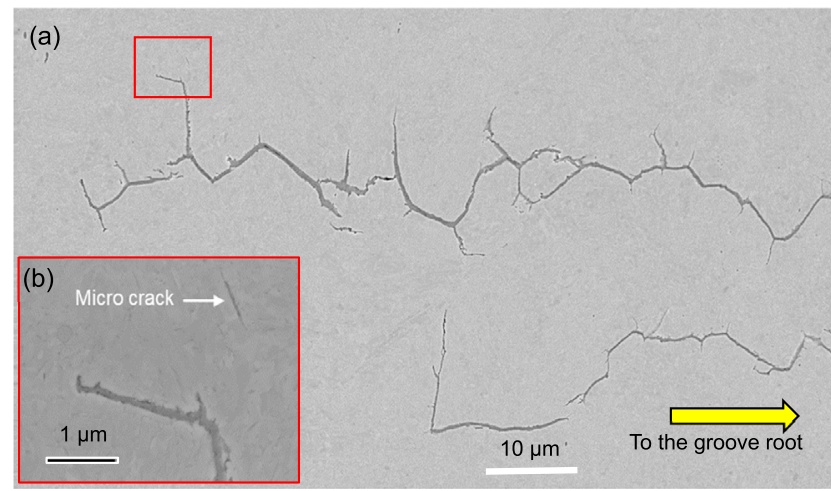

Fig. 11. (a) SEM micrograph showing multiple nucleation and branching of cracks in an area about $200 \mu \mathrm{m}$ from the groove root next to the fractured one. The view is a cross section parallel to the tensile axis. (b) is the magnified view of the red-framed area in (a), showing mating of irregularly-shaped and flat crack surfaces and also a separately nucleated microcrack. (Online version in color.)

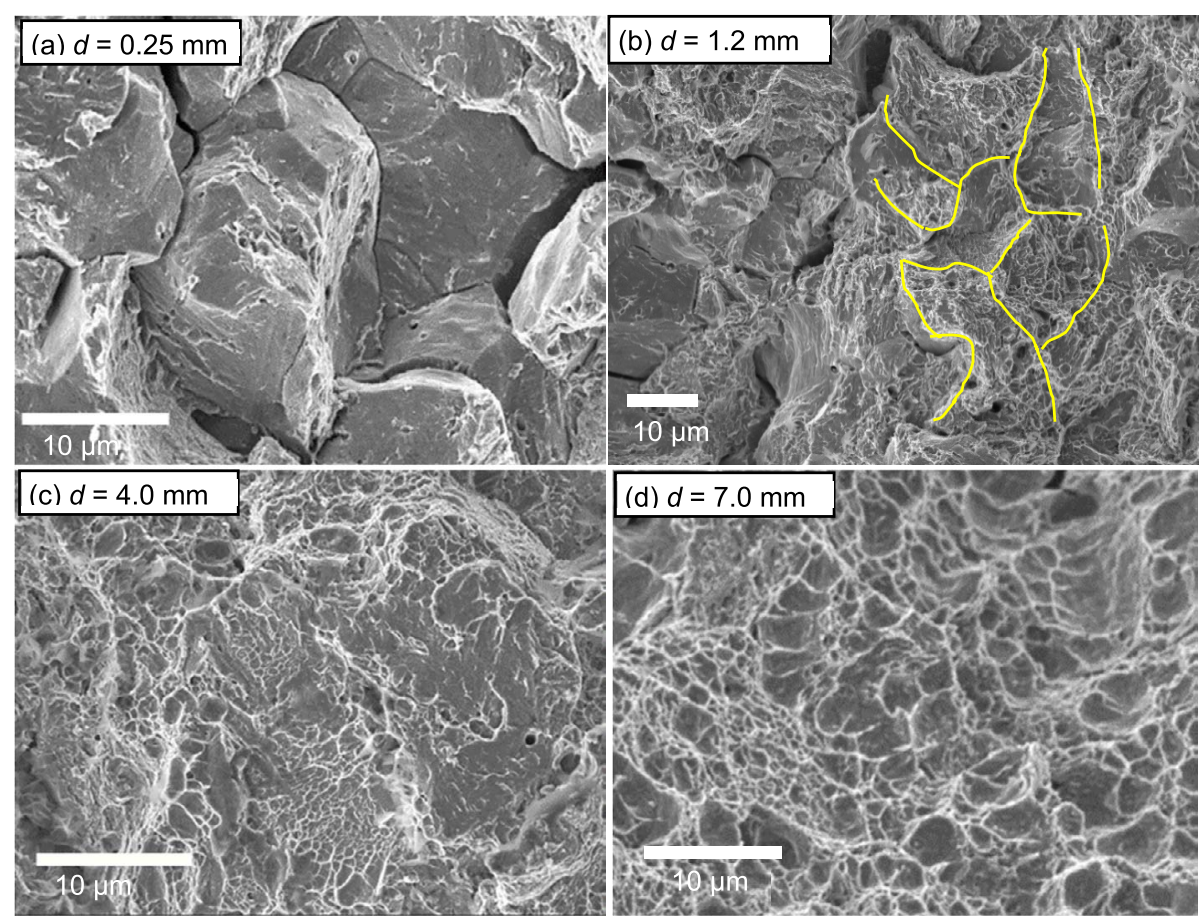

Fig. 12. Fractographic features associated with the crack advance. Panels (a)-(d) show fracture surfaces each at the indicated distance $d$ from the edge of the fracture surface as marked in Fig. 5(b). Yellow lines in (b) are estimated prior austenite grain boundaries. (Online version in color.) 
the mating of irregularly-shaped and flat crack surfaces and a separately nucleated microcrack, too.

\subsection{Crack Propagation}

\subsubsection{Alterations of Fracture Morphology}

Figure 12 shows fractographic features at sites of different distances $d$ from the edge as indicated by the letters in Fig. 5(b). Figure 12(a) is an area within the dark zone in Fig. 5(a) before the start of the striated crack propagation. The fracture was entirely IG, exhibiting sharp three-dimensional grain shapes. The configurations intensify roughness of the fracture surface, enhancing dark contrast in SEM micrograph. Opening of secondary cracks along many grain boundaries implied a substantial elastic strain and strain energy release on cracking. Shibata et al. gave a term of IG-like to IG surfaces that accompanied striations, ${ }^{44)}$ but it is difficult to make an essential distinction between IG and IGlike. Fine tear-ridges more or less decorated most of the IG fracture surface in Fig. 12(a). The fracture surface at $550 \mu \mathrm{m}$ from the edge (not shown here) was also IG similar to Fig.

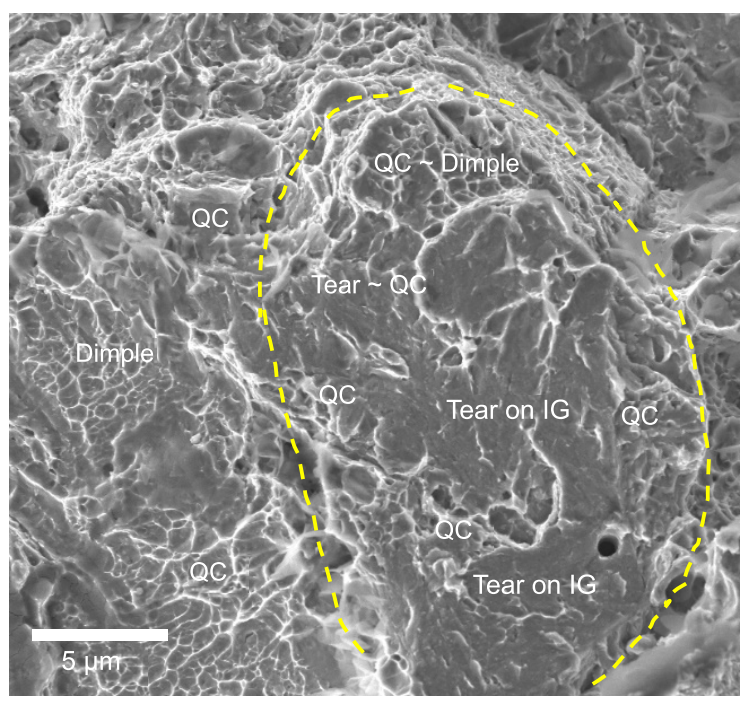

Fig. 13. Magnified view of a part of Fig. 12(c). The dotted yellow line is an estimated prior austenite grain boundary, showing co-presence of QC and fine dimples on a prior austenite grain boundary. The site is $4 \mathrm{~mm}$ from the outer surface of the bolt. (Online version in color.) 12(a). Figure 12(b) is an area a little apart from the zone where multiple cracks nucleated and then merged, forming the propagating crack, as stated in Sec. 3.1. The propagating crack starts from this zone. The fracture morphology was mixed IG and QC fracture modes. The sharpness of the IG fracture diminished, but outlines of prior austenite grains were still discernible in the QC mode. A three-dimensional configuration of grains remained in the area, but the height difference between neighboring fracture planes across grain boundaries was moderate compared to Fig. 12(a).

Figure 12(c) shows an area in the propagating crack after merging the two fracture surfaces I and II. The fracture surface was QC covered by fine and irregular networks. The area was flatter than in Fig. 12(b), and the height difference at crossing grain boundaries was substantially reduced. A further crack advance to the bolt center altered the QC mode to equiaxial fine dimples, as shown in Fig. 12(d).

The fracture surface in Fig. 12(a) is like assembles of independently nucleated grain-boundary separations. On the other hand, after the start of the propagating crack shown in Figs. 12(b)-12(d), alteration of morphologies associated with the crack advance was fairly continuous without distinctive borders. It implies that plastic deformation in the crack front continuously extended to the neighboring grain when the crack crossed grain boundaries. Figure $\mathbf{1 3}$ is a magnified view of a part in Fig. 12(c), and the dotted yellow line denotes an estimated grain boundary according to the size and flatness of the encircled area. The coexistence of tear patterns, QC, and fine dimples along a grain boundary is apparent.

\subsubsection{Fine Striations to Step-wise Crack Growth}

Periodical striations perpendicular to the crack growth direction were faintly discernible. Figure 14 shows magnified views of the area near to site c in Fig. 5(b), about 8 $\mathrm{mm}$ from the edge, obtained by tilting the specimen stage by $45^{\circ}$ to the crack growth direction to enhance the contrast. Striations about $50 \mu \mathrm{m}$ apart imply periodic crack arrest and restarting. The fracture morphology was mostly fine dimples, but QC fracture was partially present on the striation's advancing side. Crack growth likely proceeded with repeated de- and re-embrittlement of the crack front, and the kinetics of the process likely determined the crack
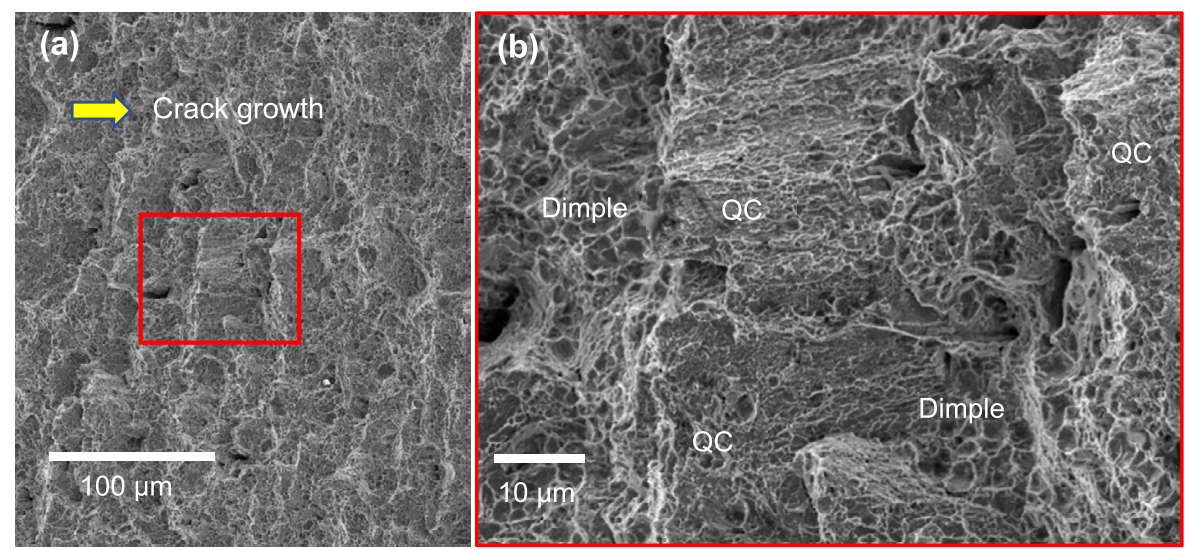

Fig. 14. (a) Striations perpendicular to the crack growth direction at a site about $8 \mathrm{~mm}$ from the edge. The specimen stage was tilted by $45^{\circ}$ to the crack growth direction in order to enhance the contrast. (b) Magnified view of the red-framed area in (a). (Online version in color.) 
growth rate.

\section{Discussion}

\subsection{Crack Initiation}

\subsubsection{Formation of Frail Zone}

A clear fracture surface without corrosion film and pits implies that delayed fracture in the present case was not a type of stress corrosion cracking to which austenitic stainless steels are susceptible. Atmospheric exposure was at a coastal site, but delayed fracture in long-term atmospheric exposure also occurred in inland regions. Fracture morphologies are typical of HE observed in tensile and bending tests, ${ }^{20,22)}$ implying that the present failure is a type of HE.

The present study revealed that the final crack propagation started not from one point but a thin zone beneath the screw groove extending about $500 \mu \mathrm{m}$ in depth and a few $\mathrm{mm}$ in length along the outer surface of the bolt (Fig. 5(b)). Multiple nucleation of cracks and their mergence were revealed in this zone (Figs. 6 and 7). Fine cracks and their link along prior austenite grain boundaries were also revealed on a cross-section parallel to the tensile axis at a few hundred $\mu \mathrm{m}$ beneath the groove root (Fig. 11). The depth of this zone was coincident with the area of intensified stress and strain (Fig. 3). Since the final crack propagation likely took place in a short period, say one week or so, deterioration of this zone might take a long time, like 16 years, until the onset of delayed fracture. We conventionally use the term "frail zone" for this deteriorated zone. The use of "frail" instead of "embrittled" evaded the latter's implication of a specific type of fracture.

Entry of hydrogen from the environment is a viable origin of the incubation time in early delayed fracture. However, the surface state must become stationary after a substantial time of exposure, and the absence of a continuous increase in hydrogen content ${ }^{7-9}$ ) suggests the operation of a driving force other than increasing hydrogen content. In this respect, some past studies that revealed carry-over of strain-induced vacancies in stress-history of steels ${ }^{45-47)}$ are suggestive of accumulation of damage or imperfections of material.

Materials under atmospheric exposure tolerate temperature and humidity variations, which induce daily variations of the hydrogen permeation current into steel. ${ }^{8,48)}$ The outcome of such effects in the delayed fracture is a matter for further studies, but past laboratory tests suggested a presumable function of environmental variations. One was that periodic variations of cathodic current density promoted delayed fracture of high-strength steels. The deterioration was prominent with increasing the variation frequency, i.e. with the number of cycles, while the supplied hydrogen content was the same. ${ }^{49)}$ In that study, the thermal desorption profile of hydrogen exhibited an increase in the density of strain-induced vacancies.

Another experiment suggesting microstructural alteration induced by hydrogen entry was the enhanced stress relaxation by hydrogen. ${ }^{50-52)}$ Stress relaxation under constant displacement conditions manifests local plasticity. An enhanced alteration of the internal stress field is a possible consequence of interactions between hydrogen and dislocations, activating dislocations and generating lattice defects.

When the idea of the critical amount of hydrogen is

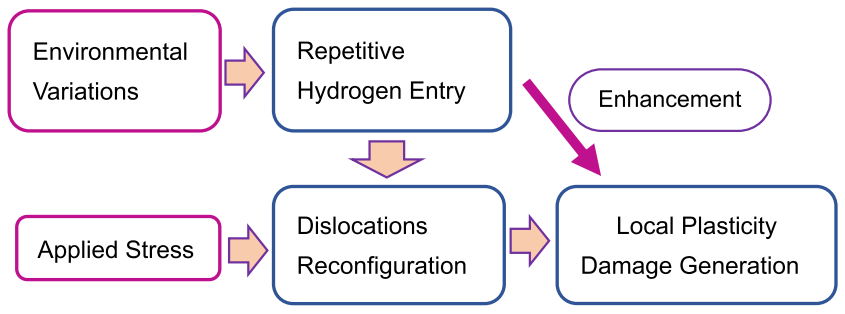

Fig. 15. The supposed process of damage accumulation under atmospheric exposure to form the frail zone. (Online version in color.)

excluded, damage of materials is a reasonable and essential factor that controls fracture event. Figure $\mathbf{1 5}$ is a presumed process of the crack nucleation under atmospheric exposure, forming the frail zone. However, direct confirmation of damage accumulation in atmospheric exposure is a matter of further study.

\subsubsection{Crack Nucleation in the Frail Zone}

The fracture mode in the frail zone was IG, which was generally considered a type of brittle fracture controlled by tensile stress. However, the IG surface in Fig. 10(b), almost parallel to the tensile axis, suggested that external tensile stress was not the primary controlling factor in the crack nucleation. The curved shape of an IG crack just beneath the outer surface of fracture surface II (Fig. 6(b)) is consistent with the crack paths along the maximum shear stress observed in four-point bending tests of notched specimens of hydrogen-charged carbon steels. ${ }^{53,54)}$ As mentioned in subsection 3.1.2, the FRASTA results did not show unique stress or strain state common to the crack nucleation on surfaces I and II.

FRASTA gives topographic information on the final fracture surface, and it does not exclude crack nucleation out of the fracture surface. The stress relief associated with crack opening redistributes the applied load to nearby unbroken material and eventually induces new cracking. A notable result of FRASTA was the multiple nucleation of cracks and their merging over a thin zone, leading to the initiation of the final crack propagation. The multiple crack nucleation implies that deterioration extends over the zone and that the sequence of crack nucleation is not likely a crucial matter.

Multiple crack formations along segregation bands of impurities and secondary particles often occur in steels in cases of high hydrogen fugacity. However, the threedimensional appearance of IG fracture (Figs. 10(b) and 12(a)) characterizes the crack nucleation in the present case. The network of fine cracks (Fig. 11) also exhibits that the prior austenite grain boundaries are preferential sites of crack nucleation. Heavily accumulated damage is a possible source of the crack nucleation, and high dislocation densities in slip bands, dislocation cell walls, and grain boundary vicinities. ${ }^{23-25)}$ provide potential crack nucleation sites. Even small excitations by environmental variations may affect dislocation configurations, inducing local plasticity that intensifies damage sites.

Damage pertinent to crack nucleation presumed in the present paper is vacancy clusters. A detailed discussion is beyond the scope of the present paper, but molecular dynamics (MD) simulations have depicted the nanoscopic 
process of the growth and coalescence of nanovoids of the order of vacancy clusters: ${ }^{55-58)}$ when the density of nanovoids is substantial, dislocations emitted from neighboring nanovoids interact to produce new nanovoids that sequentially coalesce. The models presumed coexistence of high densities of dislocations and vacancies without including hydrogen. The models are general ones of the plasticitycontrolled fracture, but the presence of hydrogen likely promotes the process. Nanovoid coalescence has been revealed for QC fracture of line-pipe steels in hydrogen gas. ${ }^{35)}$ For IG fracture, hydrogen degradation of tensile properties was exhibited for martensitic steels with different $\mathrm{Mn} / \mathrm{Ni}$ contents associated with enhanced strain-induced vacancies. ${ }^{59)}$ However, direct observations of the nanoscopic fracture process have never been reported for IG fracture.

\subsection{Crack Propagation}

\subsubsection{Affinity of Fracture Morphologies}

Fracture morphologies changed continuously from IG to QC and fine dimples concomitantly with crack propagation (Fig. 12). The fan-like contracts in Fig. 5(b) corresponds to successive changes of fractographic features, and a matter of concern is the controlling factor of the transition. An issue to be examined here is the affinity of IG with other fracture morphologies. QC and dimple fractures are definitely plasticity-dominated, but the concern of plasticity with IG fracture has been a matter of argument. The fracture morphology termed IG-like by Shibata et al $^{44)}$ as an intermediate between IG and QC suggests that the crack nucleation and propagation are associated with plasticity in the close vicinity, of the order of $100 \mathrm{~nm},{ }^{60)}$ of prior austenite grain boundaries. In the present case, the IG surfaces in the frail zone, more or less decorated with fine tear ridges (Fig. 12(a)), might be worthy of the term IG-like. A curved IG fracture likely along a slip line (Fig. 6(b)) also implies the involvement of plasticity. The inset (b) in Fig. 11 shows a branched crack along grain boundary, and mating of flat and irregularly-shaped surfaces is similar to a microcrack observed by Shibata et $a l .{ }^{60)}$ The mating of flat and irregular surfaces suggests a common origin for IG and IG-like.

Alteration of fracture morphology concomitant with crack growth was first observed and related to a decreasing stress intensity factor $K$ by Beachem in a wedge-loading test of AISI 4340 steel in a $3 \% \mathrm{NaCl}$ aqueous solution. ${ }^{61)}$ $K$ is proportional to the square root of the crack length and increases with crack growth in the present constantdisplacement fastening condition. Quantitative estimation of $K$ in the present case is difficult, but the $K$-dependence of fracture morphologies from IG to QC and fine dimples was qualitatively consistent with the literature. Beachem did not mention the origin of the $K$-dependence, but increasing $K$ would reasonably enlarge the highly stressed region in the crack front and activate dislocations therein, thus increasing the sites available for crack nucleation.

The potential crack path must incorporate inhomogeneous accumulation of hydrogen and damage. Prior austenite grain boundaries in martensitic steels operate as barriers to glide of dislocations, increasing dislocation densities in the vicinity. A preferential crack path will then be seemingly along the boundaries, retaining a three-dimensional configuration of grains consistent with observations.
A characteristic of the alteration of fracture morphologies is moderate or gradual transitions appearing as blunting of sharp prior austenite grain shapes (Fig. 12(b)), broadening of boundaries between IG and QC (Fig. 12(b)), and between QC and fine dimple surfaces (Figs. 12(c), 12(d)). A reasonable aspect of the origin of the alteration is the involvement of plasticity in front of the propagating crack. The net-like cracking along prior austenite grain boundaries shown in Fig. 11 supports the idea stated with Fig. 12(a) that independently nucleated fine cracks link along grain boundaries in the frail zone. Multiple nucleation of fine cracks suggests accumulation of damage preferentially along the grain boundaries ready to nucleate cracks there.

A presumable crack growth process is as follows. The link of microcracks on grain boundaries is surely the early stage of macroscopic crack nucleation. Sharp boundary lines may appear when the extending crack meets another one extending along a neighboring boundary. The plastic zone in front of a crack also expands associated with the crack growth and blunt the meeting boundary lines, though still keeping boundary shapes. In the early stage of crack growth, the distribution of potential cack nucleation sites may determine the crack path. Further crack growth, however, enlarges the plastic zone and intensifies stress states therein. Potential crack nucleation sites then increase, and the applied stress, rather than the distribution of the sites, will be the primary factor for the crack path. Observed changes of fractographic features (Fig. 12) are consistent with the notion that straininduced damage served as the common crack path. Different appearances of IG, IG-like, and QC might originate in the extent of void nucleation sites in the crack path. Figure 16 schematically illustrates the alteration of the crack path associated with increasing $K$, omitting proper length scales and locations from the notch root.

\subsubsection{Step-wise Crack Propagation}

Periodical striations perpendicular to the crack growth direction shown in Fig. 14(a) indicate step-wise crack propagation. The hydrogen concentration after long-term atmospheric exposure would be reasonably uniform in the region outside the frail zone at a value lower than that in the zone. When a crack propagates from the frail zone, stress intensification at the crack front will raise the hydrogen concentration therein. In this case, an external supply of

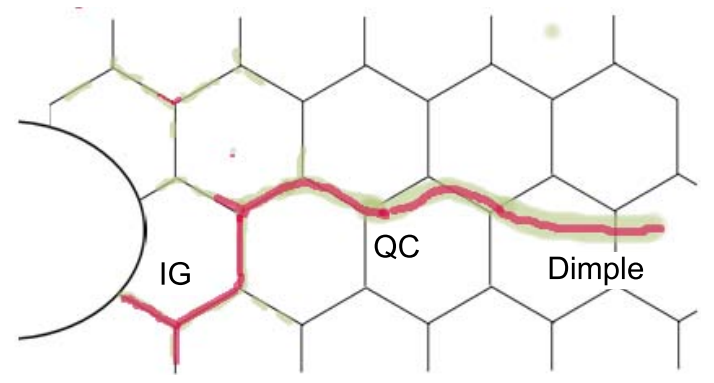

Fig. 16. Schematic illustration of the alteration of the crack propagation path from IG mode to QC mode and dimples as the crack propagates from the bottom of the screw thread. The crack and the associated damage zone are shown in red and green, respectively. (Online version in color.) 
hydrogen from the atmosphere through a thin gap formed by the crack is hardly feasible, and internal diffusion instead would be the viable supply process. The observed striations would result from the periodic crack start and stop, associated with a repeated buildup of local hydrogen concentration to the critical level.

In a quantitative aspect, Wang et al. calculated the buildup of the hydrogen concentration at the notch root using a stress-driven hydrogen diffusion equation. ${ }^{13)}$ The time required to reach a steady-state was a few hundred minutes for their experimental condition. On the other hand, in the propagating sharp crack, the crack advance is expected to occur at a hydrogen concentration of a certain level, likely that in the frail zone, before reaching the steady-state value. The local hydrogen concentration is an exponential function of triaxial stress. According to the calculated stress concentration for the circumferentially notched round bar in Fig. 3 or the screw-threaded bolt ${ }^{42)}$ the estimated maximum hydrogen concentration in the vicinity of the screw groove was not so high, likely $1.5-1.8$ times the average value $\mathrm{C}_{0}$ in the bolt. An exact quantitative estimation is difficult, but the time spent to raise the hydrogen concentration in the crack front to a critical level would be much shorter than a few hundred minutes to reach steady states $\left(3-4 \mathrm{C}_{0}\right)$ in the notch root in Wang's case. ${ }^{13)}$ In the present case, the slightly rusting fracture surface shown in Fig. 4 suggested that the crack propagated taking about one week or so. Then, the observed width of about $50 \mu \mathrm{m}$ between striations (Fig. 14) gave about 20 minutes for one-step crack advance, when assumed that the crack propagated $10 \mathrm{~mm}$ in three days. The estimated crack growth rate conforms roughly well to the order of magnitude with the calculated time for the buildup of hydrogen concentration using Wang's results. ${ }^{13)}$

The crack propagation process outside the frail zone may be similar to that in the laboratory constant-load delayed fracture test,$^{13)}$ where the supply of hydrogen is the decisive factor for cracking. Hydrogen supply will stimulate dislocation dynamics and generate additional damage to start cracking at sites where densities of dislocations and vacancies are already substantial. However, the restarted crack would be deprived of the driving force after a short advance under a constant displacement condition by a steep hydrogen concentration gradient. The situations of laboratory tests of delayed fracture under constant-load using hydrogen-enclosed notched specimens may correspond to the step-wise crack propagation stage in the present case.

\section{Summary and Conclusions}

The microscopic cracking process in delayed fracture after long-term atmospheric exposure was revealed for the first time for a high-strength steel bolt subjected to constantdisplacement loading.

(1) The final crack propagation started from a zone extending about $500 \mu \mathrm{m}$ in depth and a few $\mathrm{mm}$ in length along the outer surface beneath the screw groove where intensified stress operated accompanying local plasticity. Multiple cracks nucleated and merged over the zone to form the propagating crack. Network-like nucleation of fine cracks and their link along prior austenite grain boundaries were revealed beneath a groove root on a cross-section of the zone parallel to the tensile axis. The stress and strain states at the crack nucleation sites were not specific.

(2) Propagation of the crack was associated with alterations of fracture morphology from IG to QC and fine dimples. In the alteration of morphologies, differences between inter and trans-granular features decreased without showing distinct borders. The alteration likely results from increasing activated sites for local plasticity in the advancing crack front. Fine striations were discernible on the propagating crack surface outside the frail zone. It indicates a step-wise crack advance, and the buildup of hydrogen concentration at the crack front by internal diffusion likely limits the crack growth rate.

(3) The observed cracking process is consistent with the notion that the accumulation of damage induced by local plasticity during long-term atmospheric eventually causes the crack initiation and propagation. The deduced role of hydrogen is like a promoter of the multiple void nucleation and coalescence fracture process. Assessment of the intrinsic susceptibility to HE using a parameter that denotes the increment in strain-induced vacancies by hydrogen ${ }^{62)}$ will be helpful to delayed fracture in atmospheric exposure.

(4) Delayed fracture in atmospheric exposure takes place in a long-time span. Whether the earlier failure is similar to the present case of failure after 16 years must be examined. Precise characterization of damage and the atomistic mechanism of the cracking process is also for further studies.

\section{REFERENCES}

1) S. Matsuyama: Tetsu-to-Hagané, 80 (1994), 679 (in Japanese). https://doi.org/10.2355/tetsutohagane1955.80.9679

2) JIS B 1186: 1995, Sets of high strength hexagon bolt, hexagon nut and plain washers for friction grip joints (in Japanese).

3) S. Yamasaki and T. Takahashi: Tetsu-to-Hagané, 83 (1997), 454 (in Japanese). http://doi.org/10.2355/tetsutohagane1955.83.7_454

4) T. Dieudonné, S. Cobo, M. Di Michele, B. Rémy and T. Sturel: Materials Performance in Hydrogen Environments, ed. by B. P. Somerday and P. Sofronis, ASME, New York, (2017), 114.

5) T. Das, K. R. Sriraman, S. V. Brahimi and S. Yue: Materials Performance in Hydrogen Environments, ed. by B. P. Somerday and P. Sofronis, ASME, New York, (2017), 132.

6) A. S. Tetelman and W. D. Robertson: Acta Metall., 11 (1963), 415

7) T. Kushida: ISIJ Int., 43 (2003), 470. https://doi.org/10.2355/ isijinternational.43.470

8) T. Omura: ISIJ Int., 52 (2012), 267. https://doi.org/10.2355/ isijinternational.52.267

9) S. Li, E. Akiyama, N. Uno, K. Hirai, K. Tsuzaki and B. Zhang: Corros. Sci., 52 (2010), 3198. https://doi.org/10.1016/j.corsci.2010.05.038

10) M. Nagumo: Fundamentals of Hydrogen Embrittlement, SpringerNature, Singapore, (2016), Chap. 6-8. https://doi.org/10.1007/978-98110-0161-1

11) H. H. Johnson, J. G. Morlet and A. R. Troiano: Trans. Metall. Soc. AIME, 212 (1958), 528.

12) A. R. Troiano: Trans. ASM, 52 (1960), 54.

13) E. Wang, E. Akiyama and K. Tsuzaki: Corros. Sci., 48 (2006), 2189. https://doi.org/10.1016/j.corsci.2005.07.010

14) ISO 16573: 2015, Steel — Measurement method for the evaluation of hydrogen embrittlement resistance of high strength steels.

15) R. A. Oriani and P. H. Josephic: Acta Metall., 22 (1974), 1065. https://doi.org/10.1016/0001-6160(74)90061-3

16) W.W. Gerberich, R. A. Oriani, M.-J. Lji, X. Chen and T. Foecke: Philos. Mag. A, 63 (1991), 363. https://doi.org/10.1080/01418619108204854

17) W. W. Gerberich, P. G. Marsh and J. H. Hoehn: Hydrogen Effects in Materials, ed. by A. W. Thompson and N. R. Moody, TMS, Warrendale, PA, (1996), 539.

18) H. K. Birnbaum and P. Sofronis: Mater. Sci. Eng. A, 176 (1994), 191. https://doi.org/10.1016/0921-5093(94)90975-X

19) H. K. Birnbaum: Hydrogen Effects on Materials Behavior, ed. by $\mathrm{N}$. R. Moody and A. W. Thompson, TMS, Warrendale, PA, (1990), 639.

20) I. M. Robertson, P. Sofronis, A. Nagao, M. L. Martin, S. Wang, D. W. Gross and K. E. Nygren: Metall. Mater. Trans. A, 46 (2015), 2323. https://doi.org/10.1007/s11661-015-2836-1 
21) P. Novak, R. Yuan, B. P. Somerday, P. Sofronis and R. O. Ritchie: J. Mech. Phys. Solids, 58 (2010), 206. https://doi.org/10.1016/j. jmps.2009.10.005

22) A. Nagao, M. Dadfarnia, B. P. Somerday, P. Sofronis and R. O. Ritchie: J. Mech. Phys. Solids, 112 (2018), 403. https://doi. org/10.1016/j.jmps.2017.12.016

23) A. M. Cuitiño and M. Ortiz: Acta Mater., 44 (1996), 427. https://doi. org/10.1016/1359-6454(95)00220-0

24) U. Essmann and H. Mughrabi: Philos. Mag. A, 40 (1979), 731. https://doi.org/10.1080/01418617908234871

25) Y. Ohashi: Philos. Mag., 98 (2018), 2275. https://doi.org/10.1080/14 786435.2018.1478142

26) M. Nagumo, M. Nakamura and K. Takai: Metall. Mater. Trans. A, 32 (2001), 339. https://doi.org/10.1007/s11661-001-0265-9

27) Y. Sugiyama and K. Takai: Acta Mater., 208 (2021), 116663. https:// doi.org/10.1016/j.actamat.2021.116663

28) Y. Sugiyama, N. Kurihara, Y. Matsumoto and K. Takai: Scr. Mater., 202 (2021), 114031. https://doi.org/10.1016/j.scriptamat.2021.114031

29) K. Sakaki, T. Kawase, M. Hirato, M. Mizuno, H. Araki, Y. Shirai and M. Nagumo: Scr. Mater., 55 (2006), 1031. https://doi.org/10.1016/j. scriptamat.2006.08.030

30) S. K. Lawrence, Y. Yagodzinskyy, H. Hänninen, E. Korhonen, F. Tuomisto, Z. Harris and B. P. Somerday: Acta Mater., 128 (2017), 218. https://doi.org/10.1016/j.actamat.2017.02.016

31) K. Saito, T. Hirade and K. Takai: Metall. Mater. Trans. A, 50 (2019), 5091. https://doi.org/10.1007/s11661-019-05450-3

32) K. Sugita, M. Mizuno, H. Araki, Y. Shirai, T. Omura, K. Tomatsu and Y. Sakiyama: Tetsu-to-Hagané, 106 (2020), 20 (in Japanese). https://doi.org/10.2355/tetsutohagane.TETSU-2019-064

33) R. Kirchheim: Acta Mater., 55 (2007), 5129. https://doi.org/10.1016/j. actamat.2007.05.047

34) R. Matsumoto, N. Nishiguchi, S. Taketomi and N. Miyazaki: J. Soc. Mater. Sci., Jpn., 63 (2014), 182 (in Japanese). https://doi. org/10.2472/jsms.63.182

35) T. Neeraj, R. Srinivasan and J. Li: Acta Mater., 60 (2012), 5160. https://doi.org/10.1016/j.actamat.2012.06.014

36) M. Nagumo: Mater. Sci. Technol., 20 (2004), 940. https://doi. org/10.1179/026708304225019687

37) M. Nagumo and K. Takai: Acta Mater., 165 (2019), 722. https://doi. org/10.1016/j.actamat.2018.12.013

38) K. Takai, H. Shoda, H. Suzuki and M. Nagumo: Acta Mater., 56 (2008), 5158. https://doi.org/10.1016/j.actamat.2008.06.031

39) M. L. Martin, M. Dadfarnia, A. Nagao, S. Wang and P. Sofronis: Acta Mater, 165 (2019), 734 https://doi.org/10.1016/j.actamat.2018.12.014

40) S. Yamasaki, T. Takahashi and T. Kobayashi: Tetsu-to-Hagané, 83 (1997), 526 (in Japanese). https://doi.org/10.2355/tetsutohagane1955.83.8_526

41) Y. Kimura, T. Inoue, T. Nakata and M. Fukuda: Trans. Jpn. Soc. Mech. Eng., 84 (2018), 17-00493. https://doi.org/10.1299/ transjsme.17-00493

42) Guidebook for Evaluation of Delayed Fracture Property of High Strength Bolts, JSSC Technical Report No. 91, Japanese Society of Steel Construction, Tokyo, (2010), Chap. 4 (in Japanese).

43) T. Kobayashi and D. A. Shockey: Metall. Trans. A, 18 (1987), 1941. https://doi.org/10.1007/BF02647024

44) A. Shibata, T. Murata, H. Takahashi, T. Matsuoka and N. Tsuji: Metall. Mater. Trans. A, 46 (2015), 5685. https://doi.org/10.1007/ s11661-015-3176-x

45) M. Nagumo, S. Sekiguchi, H. Hayashi and K. Takai: Mater. Sci. Eng. A, 344 (2003), 86. https://doi.org/10.1016/S0921-5093(02)00403-3

46) T. Doshida, M. Nakamura, H. Saito, T. Sawada and K. Takai: Acta Mater., 61 (2013), 7755. https://doi.org/10.1016/j.actamat.2013.09.015

47) T. Doshida, H. Suzuki, K. Takai, N. Oshima and T. Hirade: ISIJ Int., 52 (2012), 198. https://doi.org/10.2355/isijinternational.52.198

48) K. Yamakawa: Advances in Delayed Fracture Solution, The Iron and Steel Institute of Japan, Tokyo, (1997), 77 (in Japanese).

49) M. Nagumo, H. Uyama and M. Yoshizawa: Scr. Mater., 44 (2001), 947. https://doi.org/10.1016/S1359-6462(00)00683-7

50) S. Lunarska: Scr. Metall., 11 (1977), 283. https://doi.org/10.1016/00369748(77)90202-2

51) R. A. Oriani and P. H. Josephic: Acta Metall., 27 (1979), 997. https:// doi.org/10.1016/0001-6160(79)90187-1

52) M. Nagumo, T. Tamaoki and T. Sugawara: Hydrogen Effects on Materials Behavior and Corrosion Deformation Interactions, ed. by N. R. Moody et al., TMS, Warrendale, PA, (2003), 999.

53) O. A. Onyewuenyi and J. P. Hirth: Metall. Trans. A, 14 (1983), 259. https://doi.org/10.1007/BF02651623

54) I.-G. Park and A. W. Thompson: Metall. Trans. A, 22 (1991), 1615. https://doi.org/10.1007/BF02667374

55) S. Traiviratana, E. M. Bringa, D. J. Benson and M. A. Meyers: Acta Mater., 56 (2008), 3874. https://doi.org/10.1016/j.actamat.2008.03.047

56) T. Tang, S. Kim and M. F. Horstemeyer: Acta Mater., 58 (2010), 4742. https://doi.org/10.1016/j.actamat.2010.05.011

57) Y. Zhang and S. Jiang: Philos. Mag., 97 (2017), 2772. https://doi.org /10.1080/14786435.2017.1352108

58) S. Chandra, M. K. Samal, V. M. Chavan and S. Raghunathan: Philos. Mag., 98 (2018), 577. https://doi.org/10.1080/14786435.2017.14125 91

59) M. Nagumo and H. Matsuda: Philos. Mag. A, 82 (2002), 3415. https://doi.org/10.1080/09500830500482316

60) A. Shibata, Y. Momotani, T. Murata, T. Matsuoka, M. Tsuboi and N. Tsuji: Mater. Sci. Technol., 33 (2017), 1524. https://doi.org/10.1080/ 02670836.2017 .1312210

61) C. D. Beachem: Metall. Trans., 3 (1972), 441.

62) M. Nagumo and K. Takai: Mater. Sci. Technol., 36 (2020), 1003. http://doi.org/10.1080/02670836.2019.1639009 